Ballard, M. E., Dodson, A. R., \& Bazzini, D. G. (1999). Genre of music and lyrical content: Expectation effects. The Journal of Genetic Psychology, 160(4): 476-487. (Dec 1999) Published by Taylor \& Francis (ISSN: 1940-0896).

\title{
Genre of music and lyrical content: expectation effects
}

Mary E. Ballard, Doris G. Bazzini, and Alan R. Dodson

\begin{abstract}
This study was designed to examine whether people's expectations differ regarding how music lyrics affect individual behavior as a function of music genre. Because legislative attention and media publicity have been biased against certain types of popular music (i.e., heavy metal and rap), the authors expected that those genres of music would be viewed more negatively than other genres of popular music, for which there has been little or no negative publicity (i.e., pop and country). Participants ( $N=160$ college students) rated their perceptions of how the lyrical content of a song would affect listeners' behavior. The authors presented prosocial or antisocial lyrical passages to students $(\mathrm{N}=160)$ under the guise of four musical genres (heavy metal, rap, pop, and country). Participants rated the potential impact of the lyrics on listeners' behavior. Findings indicated that lyrics labeled as heavy metal or rap were perceived as less likely to inspire prosocial behavior but not more likely to inspire antisocial behavior than the same lyrics labeled as country or pop.
\end{abstract}


Historically, there has been a distrust of youth-oriented music. Twenty-five centuries ago, Plato said, "Any musical innovation is full of danger to the whole state, and ought to be prohibited" (cited in Fox \& Williams, 1974, p. 352). More recently, detractors of rock music (e.g., Gore, 1987; Wass, Miller, \& Redditt, 1991) have maintained that some music and lyrics promote antisocial behavior among adolescents (see Ballard \& Coates, 1995, for a review).

Subsequently, a music labeling system was developed in the United States to warn consumers of lyrics containing strong language or themes of sex, violence, or substance abuse. Many people believe that listening to rock music (especially heavy metal and rap) results in antisocial behavior, despite the lack of empirical evidence to support such a belief. We examined whether expectation effects exist between music genres and behavior. Specifically, in light of biased publicity on the issue, we investigated whether heavy metal and rap lyrics are perceived as affecting behavior more negatively than lyrics from other genres of music, namely, pop and country.

\section{MUSIC GENRES}

The lyrical content of the musical genres selected for this study (heavy metal, rap, pop, and country) includes a variety of prosocial and antisocial themes. However, the media and legislators have focused on antisocial lyrics, primarily from the heavy metal and rap genres, because of their presumed harmful effects on young, impressionable listeners.

Heavy metal lyrics often have themes of alienation, retribution, and angst (Arnett, 1996; Trzcinski, 1992). The lyrics may contain references to sex, drug use, suicide, Satanism, and violence (Arnett, 1996; Bashe, 1985; Gore, 1987). From the listener's standpoint, the lyrics are secondary to the loud, guitar-driven music and may be difficult to comprehend (Hansen \& Hansen, 1991). Furthermore, heavy metal lyrics are often metaphorical and open to interpretation (Arnett, 1996; Fox \& Williams, 1974; Trzcinski, 1992).

Rap lyrics are chanted and accompanied by rhythmic music that may include dragging a phonograph needle across a record; the lyrics of rap songs are usually easy to comprehend. Rap lyrics, which sometimes contain objectionable language, often expound on the problems of urban life (Simpson, 1990), sometimes including themes of sex, drug use, misogyny, or violence (Epstein, Pratto, \& Skipper, 1990). Like heavy metal, rap lyrics often express themes of alienation and powerlessness among youth (Epstein et al.).

Pop music lyrics address a myriad of themes and include references to sex, violence, drug use, and Satan, or they may contain objectionable language (Gore, 1987; Prinsky \& Rosenbaum, 1987). Pop music reaches a larger audience than either heavy metal or rap music does.

Country music emphasizes lyrics while de-emphasizing melody and tonal complexity, so the songs generally tell a clearer story than rock songs do (DiMaggio, Peterson, \& Esco, 1972). Antisocial and depressive lyrical themes such as alcohol and drug use (Conners \& Alpher, 1989; King, 1976), promiscuity (Singletary, 1983), sexual infidelity (Chandler \& Chalfant, 1985), 
and sadness (Chalfant \& Beckley, 1977; Conners \& Alpher, 1989; Lewis, 1989; Peterson, 1992) are common in country music.

\section{LYRICAL INFLUENCE}

The antisocial themes common in popular music have compelled some adults to rally against it, especially heavy metal and rap. However, several researchers (e.g., Desmond, 1986; Greenfield et al., 1987; Prinsky \& Rosenbaum, 1987) have found that adolescents often do not comprehend or correctly interpret the messages of the rock songs' lyrics. Regardless of their understanding of lyrical messages, adolescents cite lyrical content as the least important reason for liking a song (Gantz, Gartenberg, Pearson, \& Schiller, 1978; Rosenbaum \& Prinsky, 1987). A combination of rhythm, vocals, music, and melody affects music preference, not lyrical content per se (Christenson, 1992; White, 1985).

There are correlational relationships between music preference and antisocial behavior (Wass et al., 1991), including suicide (Stack \& Gundlach, 1992). Research, however, does not substantiate a causal link between music lyrics and antisocial behavior (Arnett, 1991, 1996). Epstein and Pratto (in press) found that listening to heavy metal music did not negatively affect behavior. Arnett (1991) and McNamara and Ballard (1999) found that male adolescents may prefer arousing music because they may have a propensity toward sensation-seeking activities and lower resting arousal (i.e., heart rate and blood pressure while at rest). So, the antisocial behaviors that some rock fans engage in may be concomitant with sensation-seeking activities (Arnett, 1991) or resting arousal (McNamara \& Ballard, 1999). Also, music preference may follow, rather than precede, antisocial behavior and peer-group affiliations in adolescence (Verden, Dunleavy, \& Powers, 1989).

\section{LABELING AND MEDIA INFLUENCE}

Despite the commonality of antisocial lyrical themes and objectionable language across popular music genres, most lyrics labeled as "explicit content" by the record industry are from rap and heavy metal recordings (Christenson \& Roberts, 1998; Gilmore, 1990; Neely 1992; Thigpen, 1993). Although rap and heavy metal lyrics are more likely than other genres to contain objectionable words, pop and country lyrics with explicit language or themes (e.g., songs by Alanis Morissette, Ben Folds Five, Hank Williams, Jr.) are rarely labeled as to content. Heavy metal and rap CDs sometimes have an explicit content label even when the content is not objectionable.

Heavy metal music and rap have been the focus of negative media attention (Binder, 1993; Christenson \& Roberts, 1998). The media have suggested that heavy metal and rap lyrics promote Satanism, bigotry, sexism, violence, suicide, reckless behavior, drug use, deviant sexual activity, rape, and murder (Arnett, 1991; Epstein et al., 1990; Hansen \& Hansen, 1991; Katz, 1993; Trzcinski, 1992; Verden et al., 1989; Wass et al., 1988). There has been little condemnation of other music genres, regardless of common antisocial themes and 
objectionable language (Binder, 1993; Christenson \& Roberts, 1998; Singletary, 1983).

Moreover, if a rap star (e.g., Snoop Dog) exhibits antisocial behavior, the media are more likely to link such an incident to rap music than they are to link a country (e.g., Willie Nelson) or pop (e.g., George Michael) singer's antisocial behavior to his or her genre of music.

Because record labeling and media stories tend to link heavy metal and rap, but not pop or country, with antisocial behavior, the public may form an expectation that heavy metal and rap lyrics are more likely than lyrics from other genres to cause listeners to engage in antisocial behaviors, despite a lack of empirical evidence to support this claim (Hamilton \& Gifford, 1976; Ickes, Patterson, Rajecki, \& Tanford, 1982). This line of research is important, because such preconceptions may (a) affect the way adolescents who listen to heavy metal and rap are viewed by their parents, peers, and teachers; and (b) make adults less likely to monitor the content of music genres other than heavy metal and rap, despite the possibility that the content in the lyrics of other popular music genres might be objectionable.

\section{HYPOTHESES}

We explored participants' perceptions of the effects of lyrics from different music genres on listeners' behavior. We presented one of two sets of lyrics (antisocial or prosocial) to participants as heavy metal, rap, pop, or country music lyrics. Our hypotheses were as follows: (a) Lyrics labeled as heavy metal or rap will be perceived as more likely to inspire antisocial or maladaptive behaviors than the same lyrics labeled as country or pop; (b) lyrics labeled as heavy metal or rap will be perceived as less likely to inspire prosocial or adaptive behaviors than the same lyrics labeled as country or pop; (c) lyrics with an antisocial message will be perceived as more likely to inspire antisocial behavior than lyrics with a prosocial message, regardless of music genre; (d) lyrics with a prosocial message will be perceived as more likely to inspire prosocial behaviors than lyrics with an antisocial message, regardless of music genre.

\section{METHOD}

\section{Participants}

The participants were 160 (65 male, 94 female, and 1 unidentified) undergraduate psychology students $(\mathrm{M}$ age $=18.8$ years) who received extra credit for participation. The participants were representative of the student body of the university in terms of socioeconomic status (middle to upper middle class) and race (98\% White; $2 \%$ African American). The four music genres (heavy metal, rap, pop, and country) were crossed with two lyrical messages (antisocial or prosocial), resulting in eight conditions. Twenty participants were randomly assigned to each condition; the cells were well balanced for gender and music preference. 


\section{Materials}

Lyrics. Antisocial and prosocial lyrics were chosen in a pilot study $(\mathrm{N}=118)$ for use in the experiment. In the pilot study, six word-processed sets of lyrics were presented to the participants. The lyrics were from obscure songs that could be presented as belonging to any of the musical genres used in the study. The three antisocial lyrics contained references to sexual promiscuity, alcohol and drug use, violence, Satanism, suicide, or homicide. The three prosocial lyrics contained references to environmentalism; the dangers of alcohol use, drug use, and violence; homelessness; self-determination; and social responsibility. Pilot study participants rated the lyrics (on a 7-point Likert-type scale) in terms of antisocial and prosocial themes. The lyrics from the song "Give it Up" (O'Maoniai, O'Braonain, O'Toole, Barnes, \& Fehily, 1991, track 2) were chosen as the prosocial lyrics; $81 \%$ of the participants rated the theme of the lyrics as prosocial. The lyrics from the song "This Is the Night" (Johnson, 1992, track 4) were chosen as the antisocial lyrics; $92 \%$ of the participants rated the theme of the lyrics as antisocial. The antisocial lyrics $(M=5.94, S D=1.02)$ were rated as significantly more antisocial than the prosocial lyrics $(M=2.17, S D=1.21), t(117)=23.39, p$ [less than] .0001 . The word-processed lyrics from either "Give it Up" or "This Is the Night" were then presented to the 160 participants in the main study as the lyrics of a heavy metal, rap, pop, or country music song via a label at the top of the lyric sheet and via audiotaped instructions.

Questionnaire. The labels at the top of the word-processed lyric sheets differed on the questionnaires. The labels indicated the music genre from which the lyrics were supposedly extracted. Participants' interpretations of the lyrics were assessed by the question "What is the main theme being promoted by the lyrics?" The participants responded on a Likert-type scale ranging from prosocial (1) to antisocial (7). Fourteen items like those used by Wass et al. (1988) assessed participants' perceptions of the effects that listening to the song might have on the listener's behavior. Seven items tapped into antisocial and maladaptive behavior (sexual promiscuity, drug and alcohol use, violence, Satanism, suicidal ideation, rebelliousness toward authority, and a breakdown in morals), and 7 items tapped into prosocial and adaptive behavior (drug and alcohol awareness, environmentalism, social responsibility, critical thinking, honesty and integrity, empathy, and effective coping). Participants rated, on a 7-point Likert-type scale ranging from definitely no (1) to definitely yes (7), how likely the lyrics were to inspire each behavior. Other questionnaire items elicited demographic data and music preferences.

\section{Procedure}

Audiotaped instructions were played to the participants by research assistants, who were unfamiliar with the hypotheses of the study. Participants were presented with a word-processed copy of either the prosocial or the antisocial lyrics, labeled as heavy metal, rap, pop, or country. The participants were instructed to read the song lyrics and answer questions about them. The instructions explicitly referred to the genre of music from which the lyric was purportedly extracted. Participants were debriefed and thanked for their participation after they had completed the questionnaire. 


\section{RESULTS}

\section{Participants' Music Preferences}

No single musical genre was preferred by a majority of the participants. Many (24\%) reported having no favorite genre; other participants preferred alternative (16\%), country (14\%), pop $(13 \%)$, or classic rock (11\%). The remaining $22 \%$ endorsed nearly a dozen other music genres. Music preference was not controlled when we assigned participants to conditions, but an examination of the data indicated that randomization ensured that music preference was distributed equitably across conditions. Most (83\%) of the participants reported believing that people are influenced by song lyrics. Most participants reported knowing the lyrics to their favorite songs (56\%) and indicated that they often agreed with the ideas expressed in those lyrics (60\%).

\section{Rating of Main Theme}

A 2 (antisocial or prosocial message) x 4 (heavy metal, rap, pop, or country label) analysis of variance (ANOVA) was performed with the main theme $(1=$ prosocial, $7=$ antisocial $)$ of the lyrics as the dependent variable. There was no significant main effect of label and no interaction. A significant main effect of message, $F(1,3)=199.16, p$ [less than] .001, provided a validity check for lyrical theme. The antisocial message $(M=5.54, S D=1.23)$ was rated as significantly more antisocial than the prosocial message $(M=2.58, S D=1.44)$, on the prosocialantisocial Likert-type scale.

\section{Anticipated Effect of Lyrics on Antisocial Behavior}

A 2 (antisocial or prosocial message) x 4 (heavy metal, rap, pop, or country label) multivariate analysis of variance (MANOVA) was performed on the antisocial behaviors (sexual promiscuity, drug and alcohol use, violence, Satanism, suicidal ideation/attempts, rebelliousness toward authority, and a breakdown in morals) included on the questionnaire. This analysis examined the effects of label and message on participants' perceptions that the lyrics would inspire antisocial behavior. A significant main effect of message emerged, Hotelling's $F(7,145)=47.60$, $\mathrm{p}$ [less than] .001, indicating that participants expected the antisocial lyrics to be significantly more likely to inspire all seven antisocial behaviors than the prosocial lyrics (see Table 1 for univariate F statistics and means). No other significant effects emerged. 
TABLE 1

\begin{tabular}{|c|c|c|c|}
\hline $\begin{array}{l}\text { Behavioral } \\
\text { item }\end{array}$ & $\mathrm{F}$ & $\begin{array}{l}\text { Prosocial } \\
\text { message }\end{array}$ & $\begin{array}{c}\text { Antisocial } \\
\text { message }\end{array}$ \\
\hline Sexual promiscuity & 37.16 & 2.01 & $3.50\left({ }^{*}\right)$ \\
\hline Drag/alcohol use & 63.28 & 1.96 & $3.93(*)$ \\
\hline Violence/aggression & 190.75 & 1.78 & $4.78\left({ }^{*}\right)$ \\
\hline Occult or Satanism & 94.69 & 1.48 & $4.04(*)$ \\
\hline Suicidal ideation & 251.44 & 1.50 & $5.05(*)$ \\
\hline Rebelliousness & 19.78 & 2.76 & $3.99\left({ }^{*}\right)$ \\
\hline Breakdown in morals & 64.93 & 2.15 & $4.39\left(^{*}\right)$ \\
\hline
\end{tabular}

Anticipated Effect of Lyrics on Prosocial Behaviors

A 2 (antisocial or prosocial message) x 4 (heavy metal, rap, pop, or country label) MANOVA was performed on the prosocial behaviors (drug and alcohol awareness, environmental awareness, social responsibility, critical thinking, honesty and integrity, and effective coping) included on the questionnaire. In this analysis, we examined the effects of label and message on participants' expectations that the lyrics would inspire prosocial behavior. There were significant main effects for both label, Hotelling's $F(7,145)=21.91, p$ [less than] .01, and message, Hotelling's $F(7,145)=65.77, p$ [less than] .001 , but these were qualified by a significant Label x Message interaction, Hotelling's $F(7,145)=1.73, p$ [less than] 025 . Univariate follow-up tests indicated significant interactions for three of the seven prosocial behaviors: social responsibility, $F(3,152)=6.64$, $p$ [less than] .001 ; critical thinking, $F(3,152)=$ 3.60, p [less than] .05; and honesty and integrity, $F(3,152)=5.21, p$ [less than] .01; and a strong trend for a fourth, coping, $F(3,152)=2.52, p=.06$.

Simple effects tests (one-way ANOVAs holding message constant, followed by Tukey's tests, set at $p$ [less than] .05, to control for family wise error) were performed to tease apart the interaction of label and message on participants' expectations that the lyrics would promote prosocial behaviors. When the lyrics were prosocial, label did not predict participants' expectations regarding prosocial behavior. However, when the lyrics were antisocial, those labeled as heavy metal, rap, or pop were rated as less likely to inspire prosocial behaviors than the lyrics labeled as country or pop (see Table 2 for the means). The antisocial lyric was rated as significantly less likely to inspire critical thinking, $F(3,76)=6.54$, $p$ [less than] .001, and coping, $F(3,76)=5.65$, $p$ [less than] .001 , when labeled as heavy metal or rap than when labeled as country or pop. The antisocial lyric, when labeled as heavy metal, rap, or pop, was rated as significantly less likely to inspire honesty and integrity, $F(3,76)=7.12, p$ [less than] .001 , and social responsibility, $F(3,76)=9.29$, $p$ [less than] .001 , than when labeled as country. 
TABLE 2

$\begin{array}{lc}\text { Simple Effects Test Means for Prosocial Behavior } \\ \text { Behavior/genre } & M \\ \text { Social responsibility } & \\ \text { Country } & 3.95\left(^{*}\right) \\ \text { Pop } & 2.40 \\ \text { Heavy Metal } & 2.25 \\ \text { Rap } & 2.30 \\ \text { Critical thinking } & \\ \text { Country } & \\ \text { Pop } & 4.95\left(^{*}\right) \\ \text { Heavy Metal } & 3.75\left(^{*}\right) \\ \text { Rap } & 2.85 \\ \text { Honesty and integrity } & 3.20 \\ & \\ \text { Country } & \\ \text { Pop } & 3.70\left(^{*}\right) \\ \text { Heavy Metal } & 2.50 \\ \text { Rap } & 2.05 \\ \text { Coping } & 1.85 \\ \text { Country } & \\ \text { Pop } & \\ \text { Heavy Metal } & \\ \text { Rap } & \\ \text { * p [less than] .05. } & 3.35\left(^{*}\right) \\ & 2.80\left(^{*}\right) \\ & 2.10 \\ & \end{array}$

\section{DISCUSSION}

Overall, the results provide evidence that both message and labeled genre of music affected the way participants assessed the potential impact of lyrics on listeners. The hypothesis that lyrics labeled as heavy metal or rap would be perceived as more antisocial or as more likely to inspire antisocial behaviors than the same lyrics labeled as country or pop was not supported.

However, three of the hypotheses were supported: (a) Lyrics labeled as heavy metal or rap were perceived as less likely to inspire prosocial and adaptive behaviors than the same lyrics labeled as country or pop; (b) lyrics with an antisocial message were perceived as more likely to inspire antisocial behavior than lyrics with a prosocial message, regardless of genre of music; and (c) lyrics with a prosocial message were perceived as more likely to inspire prosocial behaviors than lyrics with an antisocial message, regardless of genre of music. 
Lyrics labeled as heavy metal or rap were not rated as more likely to inspire antisocial behavior than those labeled as pop or country. However, listening to heavy metal and rap lyrics was expected to decrease listeners' prosocial or adaptive behavior. Thus, the effects of biased labeling and media attention have not created a strong perception that heavy metal and rap lyrics are linked with the antisocial behaviors examined. Rather, there seems to be a perception that heavy metal and rap lyrics, but not country and pop lyrics, are related to a decrease in socially responsible and adaptive behavior. The media's portrayal of heavy metal and rap music may generate beliefs that link the fans of this music with a lack of adaptive behavior rather than active deviance. Heavy metal fans, for example, have been characterized as misfits, despite evidence to the contrary (Arnett, 1996). Country and pop music, on the other hand, may be viewed as more "wholesome" and, consequently, expected to be related to higher levels of adaptive functioning.

Clearly, the antisocial lyric was expected to produce more undesirable behavior (more antisocial and less prosocial) than the prosocial lyric. Most (83\%) of this sample reported a belief that messages contained in lyrics affect behavior. Thus, these participants expected that people who listen to antisocial lyrics will engage in more antisocial or maladaptive behaviors. Likewise, the prosocial lyric was expected to increase levels of prosocial and adaptive behavior. Thus, although there is no empirical evidence that lyrics have a direct effect on behavior or mood (Ballard \& Coates, 1995), the public seems to have the perception that popular songs differentially affect behavior, dependent on lyrical message.

There are a few limitations to the present study. First, we did not control for participants' favorite musical genre, which was skewed with respect to the four music genres. However, analyses that excluded country and pop fans(1) indicated that label effects, not music preference, accounted for the more favorable perceptions of country and pop. In future studies, controlling for music preference may increase the validity and reliability of the results.

Second, the lyrics were presented in written form, not within a musical context. Although it would be difficult to create several musical interpretations for one lyric, our hypotheses could be tested more realistically if the lyrics were presented in the musical context of each genre. Nonetheless, the present study indicates that bias exists against some musical genres in the absence of music.

Finally, our sample was relatively homogeneous and representative of only a small segment of society. However, if our young people - the target audience for much of popular music - display the biases in regard to popular music that we found, intuitively it seems that the mainstream adult population would display an even greater bias against heavy metal and rap music (or toward country music). Another concern focuses on the ethnic homogeneity of our sample. Rap music has traditionally been associated with African American youth, but it is widely popular across ethnic lines among adolescents and young adults (Christenson \& Roberts, 1998). In this sample, rap music was slightly, but not significantly, more popular than heavy metal music (heavy metal is most popular among White male youth). Thus, the biases against rap music in this sample do not appear to be ethnically based. 
In sum, the results of this study indicate that both lyrical message and purported genre of music affect expectations of the impact of lyrics on behavior. In particular, antisocial versus prosocial messages are perceived to affect antisocial and prosocial behavior (despite the lack of scientific evidence that this is so). In addition, purported genre of music affected perceptions of the impact that a song would have on the occurrence of prosocial behavior. Specifically, antisocial lyrics were perceived to have the most detrimental impact on prosocial behavior when presented as heavy metal or rap lyrics. On the other hand, lyrics labeled as country were perceived in a more positive light.

These results have a few practical implications. First, young people who listen to heavy metal and rap music might be expected to behave less prosocially and might, consequently, be treated differently by adults and peers than fans of other types of music. In addition, because of the positive biases toward country and pop music, adults might be less likely to monitor the listening habits of young people who prefer country or pop than the listening habits of those who prefer rap and heavy metal.

1 To ensure that these results were not an artifact of music preference, we ran these analyses excluding country and pop fans. Despite the loss in power, similar results were found: social responsibility, $F(3,109)=3.08$, $p$ [less than] .05; critical thinking, $F(3,109)=2.12$, $p$ [less than]. 10 ; honesty and integrity, $F(3,109)=4.46$, $p$ [less than] .01 ; coping, $F(3,152)=1.85, p=.14$. 


\section{REFERENCES}

Arnett, J. (1991). Heavy metal music and reckless behavior among adolescents. Journal of Youth and Adolescence, 20, 573-592.

Arnett, J. (1996). Metal heads: Heavy metal music and adolescent alienation. Boulder, CO: Westview Press.

Ballard, M. E., \& Coates, S. (1995). The immediate effects of homicidal, suicidal, and nonviolent heavy metal and rap songs on the moods of college students. Youth \& Society, 27, 148-168.

Bashe, P. (1985). Heavy metal thunder. Garden City, NY: Doubleday.

Binder, A. (1993). Constructing racial rhetoric: Media depictions of harm in heavy metal and rap music. American Sociological Review, 58, 753-769.

Chalfant, H. P., \& Beckley, R. E. (1977). Beguiling and betraying: The image of alcohol use in country music. Journal of Studies on Alcohol, 38, 1428-1433.

Chandler, C. R., \& Chalfant, H. P. (1985). The sexual double standard in country music song lyrics. Free Inquiry in Creative Sociology, 13, 155-159.

Christenson, P. (1992). The effects of parental advisory labels on adolescents' music preferences. Journal of Communication, 42, 106-113.

Christenson, P. G., \& Roberts, D. F. (1998). It's not only rock and roll: Popular music in the lives of adolescents. Cresskill, NJ: Hampton Press.

Conners, J. G., \& Alpher, V. S. (1989). Alcohol themes within country-western songs. The International Journal of the Addictions, 24, 445-451.

Desmond, R. J. (1986). Adolescents and music lyrics: Implications of a cognitive perspective. Communication Quarterly, 39, 276-284.

DiMaggio, P., Peterson, R. A., \& Esco, J., Jr. (1972). Country music: Ballad of the silent majority. In R. Denisoff \& R. Peterson (Eds.), The sounds of social change (pp. 38-55). Chicago: Rand McNally.

Epstein, J. S., \& Pratto, D. J. (in press). Heavy metal rock music, juvenile delinquency and Satanic identification. Popular Music and Society.

Epstein, J. S., Pratto, D. J., \& Skipper, J. R., Jr. (1990). Teenagers, behavioral problems, and preferences for heavy metal and rap music: A case study of a southern middle school. Deviant Behavior, 11, 381-394.

Fox, W., \& Williams, J. (1974). Political orientation and music preference among college students. Public Opinion Quarterly, 38, 352-371. 
Gantz, W., Gartenberg, H. M., Pearson, M. L., \& Schiller, S. O. (1978). Gratifications and expectations associated with pop music among adolescents. Popular Music and Society, 6, 8189.

Gilmore, M. (1990, December 13/27). The year in music. Rolling Stone, 593/594, 13-17, 226.

Gore, T. (1987). Raising (PG) kids in an X-rated society. Nashville, TN: Abingdon Press.

Greenfield, P. M., Bruzzone, L., Koyamatsu, K., Satuloff, W., Nixon, K., Brodie, M., \& Kingsdale, D. (1987). What is rock music doing to the minds of our youth? A first experimental look at the effects of rock music lyrics and music videos. Journal of Early Adolescence, 7, 315-330.

Hamilton, D. L., \& Gifford, R. K. (1976). Illusory correlation in interpersonal perception: A cognitive basis of stereotypic judgments. Journal of Experimental Social Psychology, 12, 392407.

Hansen, C. H., \& Hansen, R. D. (1991). Schematic information processing of heavy metal lyrics. Communication Research, 18, 373-411.

Ickes, W., Patterson, M. L., Rajecki, D. W., \& Tanford, S. (1982). Behavioral and cognitive consequences of reciprocal versus compensatory responses to preinteraction expectancies. Social Cognition, 1, 160-190.

Johnson, M. (1992). This is the night [recorded by The The]. On Dusk [CD]. Nashville, TN: Sony Songs Inc.

Katz, J. (1993, November 25). The media's war on kids: From the Beatles to Beavis and Butthead. Rolling Stone, 670, 47-49, 130.

King, L. (1976, August). The passions of the common man. Texas Monthly, 4, 98-101.

Lewis, G. (1989). Interpersonal relations and sex-role conflict in modern American country music. International Review of the Aesthetics and Sociology of Music, 20, 229-237.

McNamara, L., \& Ballard, M. E. (1999). Resting arousal, sensation seeking and music preference. Genetic, Social, and General Psychology Monographs, 125, 229-250.

O'Maoniai, L., O'Braonain, F., O'Toole, P., Barnes, L., \& Fehily, J. (1991). Give it up [Recorded by Hothouse Flowers]. On Home [CD]. Dublin, Ireland: FFRR Records Ltd.

Neely, K. (1992, August 20). Record-chain blacklist: Super Club establishes policy on rating lyrics. Rolling Stone, 18, 62.

Peterson, R. A. (1992). Class unconsciousness in country music. In M. A. McLaurin (Ed.), You wrote my life: Lyrical themes in country music (pp. 35-62). Philadelphia: Gordon and Breach Science Publishers.

Prinsky, L. E., \& Rosenbaum, J. L. (1987). Leer-ics or lyrics? Teenage impressions of rock 'n' roll. Youth \& Society, 18, 384-397. 
Rosenbaum, J., \& Prinsky, L. (1987). Sex, violence and rock 'n' roll: Youths' perceptions of popular music. Popular Music and Society, 11, 79-89.

Simpson, J. C. (1990, February 5). Yo! Rap gets on the map: Led by groups like Public Enemy, it socks a Black message to the mainstream. Time, 60-62.

Singletary, M. W. (1983). Some perceptions of the lyrics of three types of music: Rock, country and soul. Popular Music and Society, 9, 51-63.

Stack, S., \& Gundlach, J. (1992). The effect of country music on suicide. Social Forces, 71, 211218.

Thigpen, D. (1993, September 16). Restricted access. Rolling Stone, 13.

Trzcinski, J. (1992). Heavy metal kids: Are they dancing with the devil? Child \& Youth Care Forum, 21, 7-22.

Verden, P., Dunleavy, K., \& Powers, C. H. (1989). Heavy metal mania and adolescent delinquency. Popular Music and Society, 13, 73-82.

Wass, H., Miller, M. D., \& Redditt, C. A. (1991). Adolescent and destructive themes in rock music: A follow up. Omega, 23, 199-206.

Wass, H., Raup, J. L., Cerullo, K., Martel, L. G., Minigione, L. A., \& Sperring, A. (1988). Adolescents' interest in and views of destructive themes in rock music. Omega, 19, 177-186.

White, A. (1985). Meaning and effects of listening to popular music: Implications for counseling. Journal of Counseling and Development, 64, 65-69. 